\title{
A formação graduada do terapeuta ocupacional no campo da saúde mental: a perspectiva de discentes e egressos ${ }^{1}$
}

\author{
Sarah Raquel Almeida Lins, Thelma Simóes Matsukura \\ Universidade Federal de São Carlos - UFSCar, São Carlos, SP, Brasil.
}

\begin{abstract}
Resumo: O objetivo deste estudo foi identificar a compreensão de discentes e egressos de cursos de graduação em Terapia Ocupacional sobre a formação para atuação no campo da saúde mental e como eles avaliam a articulação desta formação com as políticas públicas de saúde mental brasileiras. Trata-se de um estudo quantiqualitativo, que contou com a participação de 135 discentes e egressos de cursos de graduação em Terapia Ocupacional do Estado de São Paulo. Os dados, que foram coletados por meio de questionário, foram descritos e apresentados através da análise categorial. Os discentes e egressos avaliam positivamente a formação em saúde mental recebida durante a graduação, indicando segurança para atuação no campo; no entanto, vinculam a formação continuada como estratégia também necessária para a prática. Os resultados também revelam a existência de discrepâncias entre os pressupostos das políticas públicas do setor e a realidade dos serviços em que as práticas de formação acontecem. Discute-se sobre as diretrizes curriculares em vigor, a realidade dos serviços e as práticas de formação. O estudo fornece elementos para a reflexão da formação profissional no campo da saúde mental em geral, especificamente para a Terapia Ocupacional, e acrescenta aos estudos sobre a formação do terapeuta ocupacional no Brasil.
\end{abstract}

Palavras-chave: Graduação, Saúde Mental, Terapia Ocupacional.

\section{Occupational therapist graduation in the mental health field: enrolled and former students perspective}

\begin{abstract}
This study aimed to identify the comprehension of enrolled and formers Occupational Therapy students on the academic education in order to act in the mental health field; and how they evaluate the link between this education and the Brazilian health public policies. This is a qualitative and quantitative study that included 135 enrolled and former Occupational Therapy students in São Paulo state. The data collected using a questionnaire was described and presented using the categorical analysis. The enrolled and former students gave a positive evaluation to the mental health academic background received during their undergraduate course; assuring confidence to work in this field; however, they also link the continued education as a necessary strategy to practice their jobs. The outcome also shows the existence of discrepancies between the sector public policies assumption and the services reality where the practice is developed. The current curricular guidelines, services reality and education practices are under discussion. This study provides elements for a reflection on the professional education in the general mental health field, specifically for occupational therapy and ads up to the studies on the Occupational Therapist academic education in Brazil.
\end{abstract}

Keywords: Undergraduate, Mental Health, Occupational Therapy.

Autor para correspondência: Sarah Raquel Almeida Lins, Laboratório de Saúde Mental, Departamento de Terapia Ocupacional, Universidade Federal de São Carlos, Rodovia Washington Luiz, Km 235, CP 676, CEP 13565-905, São Carlos, SP, Brasil, e-mail: sarahlinsto@gmail.com Recebido em Fev. 9, 2015; 1ª Revisão em Maio 4, 2015; Aceito em Jun. 10, 2015. 


\section{Introdução}

A Constituição Federal, promulgada em 1988, deu continuidade ao debate acerca do acesso à saúde que, naquela ocasião, passou a ser direito de todos e dever do Estado. Esse debate foi consolidado através da regulamentação do Sistema Único de Saúde (SUS) em 1990, que garantiu à população o direito à gratuidade no atendimento à saúde integral, com foco na prevenção sem prejuízo aos serviços assistenciais (LOPES, 1999; CECCIM; FEUERWERKER, 2004).

Com essa nova configuração de atenção em saúde, houve a necessidade de articulação entre a Educação Superior e a estrutura de atendimento da Saúde, a fim de que a formação dos profissionais da saúde contemplasse competências e habilidades voltadas para as exigências demandadas pela população, de forma a preparar os futuros profissionais para garantir a integralidade do cuidado, considerando os princípios e diretrizes do SUS (MATEUS; MARI, 2013; CECCIM; FEUERWERKER, 2004).

Concomitante a esse contexto de mudanças no país, a promulgação da Constituição Federal, em 1988, também iniciou o debate sobre a nova Lei de Diretrizes e Bases da Educação Nacional (LDBEN), aprovada em 1996, que versa sobre a educação e a formação nos diversos níveis; porém, em relação à Educação Superior, objetivou também

[...] promover a flexibilidade, a competitividade e a avaliação do Ensino Superior no Brasil, bem como definir as diretrizes curriculares para os cursos de Graduação (DRUMMOND; RODRIGUES, 2004, p. 106).

Assim, tomando-se como referência os direitos assegurados pela Constituição Federal, o SUS vigente no país, a LBDEN e, visando à necessidade de aprimoramento da formação dos profissionais $\mathrm{da}$ saúde, o Ministério da Educação (MEC), através da Câmara de Educação Superior (CES) e do Conselho Nacional de Educação (CNE), estabeleceu as Diretrizes Curriculares dos Cursos de Graduaçáo da Saúde (DCN) (BRASIL, 2002). Desse modo, o debate acerca da reforma da educaçáo superior nos cursos da saúde e a autonomia da universidade trouxeram novas perspectivas para a formação, que passaria a ter um novo enfoque, ou seja, a atenção em saúde de modo integral.

Assim, para integrar a formação dos profissionais da saúde, entre os anos de 2001 e 2002, foram aprovadas as Diretrizes Curriculares Nacionais (DCN) dos seguintes cursos de graduação em saúde: Biomedicina, Fisioterapia, Fonoaudiologia, Terapia
Ocupacional (TO), Medicina e Odontologia. Ceccim e Feuerwerker (2004) discutem que, apesar destas orientaçóes, o processo de formação dos profissionais em saúde necessita de mudanças que devem partir das políticas do SUS, através de claras indicações sobre as açôes na formaçáo destes profissionais, além de conter elementos indispensáveis que garantam "[...] o perfil de competências profissionais necessário à consolidaçáo do sistema de saúde [...]”, incluindo a integralidade na gestáo setorial e na formação dos profissionais em saúde, e náo apenas como eixo norteador da atenção em saúde (CECCIM; FEUERWERKER, 2004, p. 1405).

Com relação ao perfil curricular do profissional, as DCN-TO apontam para uma formaçáo generalista, humanista, crítica e reflexiva, de modo que o profissional esteja capacitado para o exercício profissional em todas as dimensôes, tanto no campo clínico-terapêutico quanto preventivo, que seja conhecedor dos fundamentos históricos, filosóficos e metodológicos da $\mathrm{TO}$, considerando a ética profissional e os diferentes modelos de intervenção, baseados no rigor científico e intelectual (BRASIL, 2002), e que atue em diferentes níveis de complexidade do SUS (OLIVER et al., 2012).

Uma das dimensóes presentes nas DCN-TO aponta que as práticas terapêuticas devem ocorrer gradativamente durante todo o curso de graduação, não ficando restritas ao período de estágio profissionalizante. Além disso, determina-se que os serviços ou clínicas terapêuticas devem abranger todas as áreas da terapia ocupacional previstas no currículo (BRASIL, 1997).

Porém, apesar dessas orientaçôes, estudos nacionais sobre a formação do terapeuta ocupacional para atuaçáo no SUS em diversos campos apontam lacunas na formação e revelam a necessidade de melhor capacitação profissional (BUENO, 2013; GOZZI, 2013; OLIVER et al., 2012; MARINS; EMMEL, 2011; CARVALHO; MATSUKURA, 2011; MÂNGIA; MURAMOTO; MARQUES, 2010; CARDOSO; CARRETA, 2007).

No que se refere ao campo da saúde mental e, apesar da diferença de cerca de dez anos, os estudos de Hahn (1999) e Mângia, Muramoto e Marques (2010), que envolveram a participação de egressos de Terapia Ocupacional - no estudo de Hahn (1999), realizavam especialização/aprimoramento em Psiquiatria e Saúde Mental, e no estudo de Mângia, Muramoto e Marques (2010), estavam inseridos em serviços ou projetos de saúde mental no contexto do SUS -, apresentaram resultados similares no que se refere à necessidade de capacitação dos egressos de cursos de graduação em Terapia Ocupacional para atuação no campo da 
saúde mental, devido, principalmente, às exigências da prática, que incluem as mudanças nas políticas públicas de saúde mental e nos modelos de atenção.

Diversamente, Ballarin e Carvalho (2007, p. 168) ressaltam o engajamento dos terapeutas ocupacionais no processo, ainda em curso, da transformação da assistência psiquiátrica brasileira, indicando a existência de novos modos de pensar e fazer a atençáo em saúde mental nos serviços substitutivos criados, com destaque para o trabalho em equipe em um ambiente interdisciplinar,

[...] onde as possibilidades de participação dos diferentes atores e categorias profissionais podem propiciar a superação de práticas desarticuladas e fragmentadas.

Não obstante, estudos nacionais recentes indicam que os terapeutas ocupacionais referem que a formação recebida na graduação não tem contemplado demandas da prática no campo da saúde mental (MÂNGIA; MURAMOTO; MARQUES, 2010; GOZZI, 2013; BUENO, 2013). Nayar (2011) aponta também que o profissional de Terapia Ocupacional busca na formação complementar o aprimoramento das habilidades em saúde mental, a fim de adquirir mais segurança para a atuação prática.

A formação de profissionais para atuação no campo da saúde mental tem sido debatida na Terapia Ocupacional e em outras especialidades, e há a compreensão de que a mudança na assistência em saúde mental no sistema de saúde brasileiro - de um sistema hospitalocêntrico, pautado na exclusão do doente mental, para um enfoque comunitário, onde o foco é a inserção ou reinserção do indivíduo na sociedade - resultou na emergência da formação de profissionais com esta nova visão de atenção em saúde mental (MATEUS; MARI, 2013; BERTAGNONI et al., 2012; MÂNGIA; MURAMOTO, 2009; MATEUS, 2009; BALLARIN; CARVALHO, 2007). E, para Mateus e Mari (2013), apesar do reconhecimento de que a formaçáo de profissionais de saúde mental é prioritária na política brasileira, ainda não houve a efetivação de estratégias para essa finalidade.

Dessa forma, verifica-se a necessidade de melhor compreender como se dá a formação na graduação de Terapia Ocupacional em um campo de atuação tradicional e em transformação, que é a saúde mental, à luz das políticas públicas do campo e considerando-se as diretrizes curriculares da área.

Considera-se que estudos sob este enfoque podem contribuir para o conhecimento e para reflexóes acerca do processo de formação teórica e prática do terapeuta ocupacional em geral e, especificamente, em nível de graduação.
Nesta direção, este estudo teve o objetivo de compreender, sob a ótica de discentes e egressos de cursos de graduação em Terapia Ocupacional do Estado de Sáo Paulo, a formação do terapeuta ocupacional em saúde mental. Buscou também verificar a articulação desta formação com as políticas públicas do campo e com as diretrizes curriculares da Terapia Ocupacional.

\section{Método}

Este estudo ${ }^{2}$ está atrelado à pesquisa mais ampla ${ }^{3}$, é do tipo transversal descritiva (SAMPIERI; COLLADO; LUCIO, 2006), de abordagem quantiqualitativa.

Foram participantes do estudo 135 discentes e egressos de dez cursos de graduação em Terapia Ocupacional do Estado de São Paulo. Os discentes estavam no último ano do curso e os egressos o haviam concluído havia, no máximo, seis meses; porém, ambos haviam realizado os estágios profissionalizantes em saúde mental.

Para a coleta de dados, utilizou-se um questionário elaborado pelos autores a partir de revisão de literatura, sendo submetido à avaliaçáo de especialistas e pesquisadores na área, e à aplicação-piloto. $\mathrm{O}$ instrumento foi composto por questôes abertas e fechadas, que versaram sobre a formação em saúde mental, a articulação com as políticas públicas, a segurança para atuação, sugestóes para a formação, dentre outras.

Para a localização dos participantes, foram convidados a participar da pesquisa 14 dos 22 cursos de graduação em Terapia Ocupacional do Estado de São Paulo registrados no INEP, na ocasião da coleta de dados ${ }^{4}$, e que contavam com, pelo menos, cinco anos de funcionamento e turmas de último ano ativas. Destes, dez coordenadores do curso (cinco de natureza pública e cinco de natureza privada) consentiram a participaçáo no estudo e concederam nomes e $e$-mails dos discentes e egressos que respondessem aos critérios de participação ou, então, indicaram um aluno-chave, que informou o contato dos colegas de turma.

Do total de 241 discentes e egressos indicados para participação no estudo, 32 foram excluídos por não cumprirem os requisitos da pesquisa ou por ocorrerem dificuldades na localização. Assim, 209 discentes e egressos foram convidados a participar da pesquisa por mensagem eletrônica, sendo que 135 efetivaram sua participação através do preenchimento do questionário, 27 aceitaram, mas não responderam o questionário, quatro recusaram o convite e 41 não retornaram. 
Depois do aceite para participação e da assinatura do Termo de Consentimento Livre e Esclarecido, o questionário foi disponibilizado de forma presencial (45 discentes), conforme viabilidade da coordenação do curso, e através da rede mundial de computadores, a partir do aplicativo Google Docs (90 discentes e egressos).

Os dados foram organizados em planilhas no Microsoft Excel e analisados por meio da identificaçâo de categorias (BARDIN, 1977).

\section{Resultados}

O universo dos discentes e egressos participantes desta pesquisa apresentou a seguinte caracterização: 75 (66\%) eram discentes e 60 (44\%) eram egressos de cursos de graduação em Terapia Ocupacional, sendo 59 (45\%) vinculados a Instituiçóes de Ensino Superior (IES) privadas e 76 (55\%) vinculados a IES públicas; em sua quase totalidade, os participantes eram do gênero feminino $(97 \%$; 131) e tinham idade entre 21 e 37 anos.

Os discentes e egressos foram questionados sobre como eles avaliavam a formação em saúde mental recebida durante a graduação e as respostas
- classificadas em positiva, positiva com ressalva e negativa - foram organizadas em categorias, que são apresentadas na Tabela 1 .

Do total, $81 \%$ dos participantes avaliaram positivamente a formação em saúde mental e apenas $5 \%$ (7) náo se posicionaram claramente ou não responderam a questão.

Os resultados apontam que ainda que a avaliação dos participantes indique para uma formação satisfatória, com destaque para a diversidade de vivências práticas, em especial, o estágio profissional, os discentes e egressos também referem a necessidade de aprofundamento de temas relacionados ao campo e de aumento do tempo de práticas, bem como formação complementar e continuada para aprimoramento da formação, como ilustram os relatos a seguir:

Avalio de maneira satisfatória, mas também generalista, com capacidade para identificar as demandas e elaborar planos de tratamentos adequados. Porém, acredito que seria necessário uma formação mais aprofundada (aprimoramento, pós-graduação, etc) para que a minha atuação tenha sempre o maior grau de qualidade. Acredito que apenas a graduação não seja o suficiente.

Tabela 1. Opinião dos discentes em relação à sua formação em saúde mental.

\begin{tabular}{|c|c|c|c|}
\hline Resposta & Categorias & $\begin{array}{c}\text { N.o de } \\
\text { indicações }\end{array}$ & $\begin{array}{l}\text { Total } \\
\mathrm{n}(\%)\end{array}$ \\
\hline \multirow{5}{*}{ Avaliações positivas } & $\begin{array}{l}\text { Formação continuada em função da formação } \\
\text { generalista }\end{array}$ & 21 & \multirow{5}{*}{$64(48 \%)$} \\
\hline & $\begin{array}{l}\text { Destaque para as práticas realizadas ao longo do } \\
\text { curso e a diversidade de experiências }\end{array}$ & 16 & \\
\hline & Destaque para a atuação do docente/supervisor & 11 & \\
\hline & Apenas "satisfatória/ rica/ boa/ muito boa" & 10 & \\
\hline & Interesse pelo campo & 6 & \\
\hline \multirow{4}{*}{$\begin{array}{l}\text { Avaliações positivas } \\
\text { com ressalva }\end{array}$} & $\begin{array}{l}\text { Necessidade de aprofundamento de temas e } \\
\text { aumento do tempo de experiência prática }\end{array}$ & 27 & \multirow{4}{*}{$45(33 \%)$} \\
\hline & $\begin{array}{l}\mathrm{O} \text { (des)interesse pelo campo da saúde mental/ } \\
\text { o interesse por outros campos de atuação }\end{array}$ & 6 & \\
\hline & Apenas "mediana/ poderia ter sido melhor" & 6 & \\
\hline & Outros & 6 & \\
\hline \multirow{5}{*}{$\begin{array}{l}\text { Avaliações } \\
\text { negativas }\end{array}$} & $\begin{array}{l}\text { Necessidade de aprofundamento dos conteúdos e } \\
\text { aprimoramento das estratégias para o ensino }\end{array}$ & 9 & \multirow{5}{*}{$19(14 \%)$} \\
\hline & $\begin{array}{l}\text { Necessidade de atividades extracurriculares para } \\
\text { complementar a formação }\end{array}$ & 3 & \\
\hline & Defasado & 2 & \\
\hline & Faltou estágio no campo & 1 & \\
\hline & Outros & 6 & \\
\hline \multirow[t]{2}{*}{ Outros } & - & 7 & $7(5 \%)$ \\
\hline & TOTAL & & $135(100 \%)$ \\
\hline
\end{tabular}


É preciso buscar ampliar o conhecimento na área, que se caracteriza tão complexa. (P98)

Acredito que minha formação se deu muito mais em estágio que em sala de aula. A prática com o paciente foi que me deu a base e a segurança para atuar na área. (P23)

Minha formação foi muito abrangente e, o que foi um fator único, foi o contato com pacientes com diferentes patologias, além de atendimento individual e grupal em diferentes instituiçóes enriqueceu muito a formação em saúde mental. (P30)

Minha formação foi boa, creio que para me sentir mais segura necessitava de mais experiência prática e maior diversidade de campo (conhecer outras instituiçôes). (P16)

Satisfatória, mas acredito que seja necessário mais tempo de prática especifica, visto que os estágios somente acontecem no último ano. (P47)

Uma minoria dos participantes avaliou negativamente a formação em saúde mental e focalizou a necessidade de investimentos teóricos e práticos, além de reforçar a demanda pela realização de atividades que complementem a formação básica.

Os participantes também responderam se os conteúdos teóricos e práticos estavam articulados com as políticas públicas de saúde mental, e a opinião dos mesmos é predominantemente positiva (106), conforme os resultados apresentados na Tabela 2.

Dentre os comentários apresentados acerca desta questão, verificou-se que ainda que reconheçam a articulação da formação com as políticas, os discentes e egressos destacam que as mesmas nem sempre estão presentes no campo em que são realizadas as práticas de formação. Esta assertiva é ilustrada através dos seguintes relatos:

Sim. Todo o conteúdo estudado passa pela articulação com as políticas de descentralização do cuidado, da humanização e articulação de redes de suporte, bem como as diretrizes do SUS, entre outros documentos que norteiam o trabalho cotidiano, como portarias e resoluçōes. (P110)

Dentro do que é possivel, eu julgo que sim. No entanto, é muito comum, quando estamos inseridos em um serviço, observarmos que as politicas públicas existem, mas não são aplicadas. (P100)

Apesar da tentativa de se conciliar teoria e prática com as políticas públicas, o que vemos é que ainda existem lacunas importantes quanto ao que se preconiza como prestação de serviço de qualidade o que realmente é possivel de se oferecer ao usuário, levando em consideração a estrutura fisica do serviço, a acessibilidade e a formação dos profissionais que prestarão atendimento. (P98)

Os participantes também foram questionados acerca da segurança para a atuação no campo da saúde mental e a maioria das respostas foi positiva, conforme indica a Tabela 3.

Apesar de reconhecerem a diversidade de campos presentes na saúde mental e de considerarem a necessidade de maior dispêndio de tempo em atividades práticas, bem como a continuidade da formação para aquisiçáo de mais segurança para a atuação, os participantes sentem-se seguros para a prática no campo, conforme os relatos que se seguem:

Acredito que sim, consegui absorver qualé o papel do TO nessa área e os tipos de intervenção, apesar de ser uma área que tenha diversos locais diferentes para atuar (infância e adolescência, uso de álcool e outra drogas, inclusão social). (P33)

Tabela 2. Opinião dos participantes quanto à articulação entre os conteúdos teóricos e práticos, e as políticas públicas de saúde mental.

\begin{tabular}{|c|c|c|c|}
\hline Resposta & Categorias & $\begin{array}{c}\text { N. }{ }^{\circ} \text { de } \\
\text { indicações }\end{array}$ & $\begin{array}{l}\text { Total } \\
\text { n ( } \%)\end{array}$ \\
\hline \multirow{3}{*}{ Sim } & Conteúdos teóricos e práticos articulados & 64 & \multirow{3}{*}{$106(78 \%)$} \\
\hline & Confronto com a realidade dos serviços & 13 & \\
\hline & Apenas "sim" & 29 & \\
\hline Em parte & - & 20 & $20(15 \%)$ \\
\hline \multirow{5}{*}{ Não } & Foco na clínica da TO & 2 & \multirow{5}{*}{$7(5 \%)$} \\
\hline & Limites relacionados ao campo/ rede & 1 & \\
\hline & Conteúdo limitado & 1 & \\
\hline & A busca pessoal pelo conteúdo & 1 & \\
\hline & Apenas "não" & 2 & \\
\hline \multirow[t]{2}{*}{ Em branco/ Não sei } & - & 2 & $2(2 \%)$ \\
\hline & TOTAL & & $135(100 \%)$ \\
\hline
\end{tabular}


Tabela 3. Opinião dos discentes e egressos acerca da segurança para atuar no campo da saúde mental.

\begin{tabular}{|c|c|c|c|}
\hline Resposta & Categorias & $\begin{array}{c}\text { N. }{ }^{\circ} \text { de } \\
\text { indicações }\end{array}$ & $\begin{array}{l}\text { Total } \\
\text { n (\%) }\end{array}$ \\
\hline \multirow{6}{*}{ Sim } & Formação ao longo do curso & 24 & \multirow{6}{*}{$71(52 \%)$} \\
\hline & Destaque para as práticas e os estágios & 18 & \\
\hline & Afinidade com o campo & 13 & \\
\hline & Apenas "sim" & 6 & \\
\hline & Formação continuada & 5 & \\
\hline & Outros & 5 & \\
\hline \multirow{5}{*}{ Em parte/ Pouco } & Necessidade de mais prática & 13 & \multirow{5}{*}{$36(27 \%)$} \\
\hline & Teoria e prática deficientes & 6 & \\
\hline & Afinidade com o campo & 6 & \\
\hline & Formação recente & 5 & \\
\hline & Outros & 6 & \\
\hline \multirow{5}{*}{ Não } & Afinidade/dificuldade com o campo & 15 & \multirow{5}{*}{$27(20 \%$} \\
\hline & Falta de experiência prática & 6 & \\
\hline & Necessidade de formação continuada & 4 & \\
\hline & Conteúdo superficial & 1 & \\
\hline & Apenas "inseguro" & 1 & \\
\hline \multirow[t]{2}{*}{ Em branco } & - & & $1(1 \%)$ \\
\hline & TOTAL & & 135 \\
\hline
\end{tabular}

Acredito que certa insegurança sempre existe, pois nunca sabemos de tudo e o inesperado pode aparecer, mas acredito que até agora tenho traçado um caminho muito feliz na formação e prática em Saúde Mental, e acredito que tenho a contribuir tanto no atendimento à população com problemáticas de saúde mental, assim como no âmbito mais ampliado na construção da rede e politicas. (P104)

Sim. Creio que minha formação acadêmica foi extremamente rica e me sinto confiante para atuar em tal área, visto que foi essa área que escolhi seguir. (P99)

Não muito, devido ao pouco tempo de estágio supervisionado. Já que, na prática é que se aprende ainda mais se tratando de saúde mental, sendo complexa. (P27)

Sinto-me pouco segura, mas isso não se dá apenas nessa área. Acredito que dificilmente um aluno sai da graduação se sentindo preparado para atuar. (P64)

Não, pois não é uma área que me sinto à vontade para trabalhar e por preferir outras áreas. (P9)

Acredito ter iniciado uma caminhada dentro do campo de saúde mental que pode me levar a um aperfeiçoamento no futuro. Não me sinto seguro para atuar ao término da faculdade. (P21)

Os participantes foram solicitados a apresentar sugestóes contributivas para a formação em saúde mental durante a graduação e, do total de 135 participantes, apenas 23 (17\%) não apresentaram sugestôes e, destes, quatro deles consideram a formação suficiente.

As 127 respostas (alguns apresentaram mais de uma sugestão) foram categorizadas e são apresentadas na Tabela 4 .

As solicitaçóes dos discentes e egressos, em sua maioria, envolvem o aumento, a antecipação e o aprofundamento de conteúdos teóricos e práticos, bem como a necessidade de novas modalidades de ensino neste campo, como ilustram os relatos a seguir.

Que as práticas se iniciem o quanto antes durante a formação. (P54)

Ter mais prática ao longo da graduação é essencial para uma boa formação de profissionais, uma vez que embora a teoria seja a base para o conhecimento, a prática é o momento em que é possivel associar tais teorias. (P97)

Sim, que fosse discutido mais sobre as politicas públicas, pois nos concursos geralmente são as questóes que mais caem, e para entendimento sobre o que é certo ou errado na hora de agir em determinada instituição. (P38)

Professores muito bons teoricamente que tenham uma ótima didática, pois as aulas e o conteúdo são "densos", exigem uma concentração e presença grandes e se o docente náo for muito didático, fica dificil "cativar" os alunos que tem o estigma da SM. Mas eu acho que esta sugestão é um pouco difícil, pois é a habilidade de cada pessoa. (P7) 
Tabela 4. Categorias das respostas e número de indicações dos participantes sobre as sugestões apresentadas para aperfeiçoamento da formação do terapeuta ocupacional no campo da saúde mental.

\begin{tabular}{lc}
\hline \multicolumn{1}{c}{ Categorias } & $\begin{array}{c}\text { N. }{ }^{\text {o de }} \\
\text { indicações }\end{array}$ \\
\hline Ampliar/antecipar a prática em saúde mental e proporcionar diversidade de práticas & 40 \\
Ampliar e atualizar conteúdos teóricos & 29 \\
Melhorar a didática docente/as estratégias de ensino & 15 \\
Aprofundar em abordagens/modelos para a prática & 11 \\
Aumentar a carga horária teórica e prática em saúde mental & 9 \\
Articular a formação com as políticas e com a rede & 9 \\
Clarificar sobre a atuação do terapeuta ocupacional & 4 \\
Promover eventos para interação com outras IES & 4 \\
Ampliar a visão acerca da saúde mental & 4 \\
Estimular o desenvolvimento de pesquisas & 1 \\
Incentivar o autoconhecimento/saúde mental do discente & 1 \\
TOTAL & $\mathbf{1 2 7}$ \\
\hline
\end{tabular}

Estudar e debruçar-se sobre diferentes abordagens da saúde mental além da psicodinâmica, como a reabilitação cognitiva que é pouco trabalhada e de extrema riqueza para o terapeuta pensando nas funçōes executivas. (P116)

Várias sugestôes foram elencadas na categoria Ampliar e atualizar conteúdos teóricos, que agregou temas, como: psicopatologia, atuação do terapeuta ocupacional em saúde mental, políticas públicas e legislação, Terapia Ocupacional na infância e adolescência, álcool e drogas, abordagens e métodos em saúde mental, dentre outros.

\section{Discussão}

Os resultados deste estudo revelaram que discentes e egressos dos cursos de graduaçáo em Terapia Ocupacional do Estado de São Paulo avaliaram sua formação em saúde mental durante a graduaçáo positivamente $(81 \%$; 109$)$ ). Os participantes destacaram a possibilidade de vivência em diversos campos de prática como um aspecto enriquecedor da formação, pela contribuição para melhor compreensão teórico-prática da saúde mental. Porém, eles consideram a necessidade de continuidade da formação para aprimoramento da prática no campo.

Em relação à formação do terapeuta ocupacional, as Diretrizes Curriculares Nacionais do Curso de Graduação em Terapia Ocupacional (DCN-TO) orientam que esta inclua conteúdos curriculares diversificados e equilibrados nas diferentes áreas e nos níveis de atuação, a fim de assegurar a formação generalista, e incentive a continuidade do aprendizado após a formação (BRASIL, 2002).

Atualmente, algumas reflexôes sobre a formação generalista do terapeuta ocupacional vêm sendo apresentadas. Para Gozzi (2013), esta formação capacita o profissional para atuar em diversos campos de prática, ao passo que limita o aprofundamento na especificidade de cada campo, e, deste modo, há possibilidades de que o estudante tenha uma formaçáo fragilizada em relação a aspectos específicos.

Não obstante, Campos (2001) concorda que a formação generalista é positiva para a área, uma vez que a formação superespecialista é estreita e tenciona as barreiras disciplinares.

Nesta direção, Drummond e Rodrigues (2004) consideram que a formação generalista tem o objetivo de formar profissionais que atendam as dinâmicas e diversidades do contexto da saúde brasileira, incluindo as políticas públicas e as questôes relacionadas aos serviços. Para essas autoras, a formação graduada generalista não se acaba em si mesma, transformando o aluno em um agente ativo no processo de ensino-aprendizagem. Assim, ao chegar na prática, para atuar em campos específicos, o egresso busca aprimorar o conhecimento através de programas lato e stricto sensu, para melhorar a sua atuação profissional.

Os resultados deste estudo indicam que os recém-formados e alunos concluintes dos cursos de graduaçáo em Terapia Ocupacional, ao se referirem ao campo da saúde mental, reconhecem a importância da formação generalista e também compreendem que o aprimoramento e o aprofundamento devem ocorrer em um processo contínuo, como apresentado pela literatura. Neste estudo, os participantes vinculam a formaçáo continuada como uma forma de aprimorar e aprofundar conhecimentos específicos da prática, como, por exemplo, através da realização de programas de aprimoramento, especializaçáo, mestrado, doutorado, dentre outros. 
Os resultados deste estudo também revelaram que os egressos e concluintes consideram a realização de práticas e estágios essenciais para o aprendizado como um todo e para a aquisição de segurança para atuação no campo, além de destacarem a importância da realização de práticas desde o início do curso. Coerentemente, apresentam, como sugestóes para melhoria da formaçáo, o aprofundamento e o aumento do tempo de experiência prática em saúde mental, bem como a antecipação das mesmas para aprimoramento da formação, o que reforça a relevância destes aspectos na formação neste campo. Tais resultados podem ser compreendidos considerando-se também, como indica a literatura, que o contato do discente com a prática em saúde mental desde início da formação, incluindo a realização de discussóes e reflexóes sobre esta prática, dentre outras atividades, configura uma poderosa forma para preparar os discentes para atender as demandas do campo (BELTRAN et al., 2007; ALMEIDA et al., 2012).

Tem-se reconhecido que o ensino prático em saúde é uma estratégia relevante que compóe a formação dos profissionais, que contribui para o conhecimento do contexto da atenção em saúde, incluindo a familiarização, a organização da gestão do serviço, a estrutura do cuidado, além de ter como objetivo a transformação das práticas profissionais e da organização do trabalho, com foco no cuidado individual e comunitário (CECCIM; FEUERWERKER, 2004).

Assim, colocam-se o desafio e a necessidade de reflexão acerca de possibilidades de inserção no campo da saúde mental em períodos mais precoces da formação graduada, tanto no que se refere à maturidade dos discentes (idade, experiências de vida, dentre outras), como no que tange à entrada em um campo complexo, que é mais um dentre outros que compóem a área da Terapia Ocupacional.

Tal desafio - e a relevância relativa à inserção precoce e mais ampla de práticas - compôs o estudo de Beltran et al. (2007), realizado na Austrália, que focalizou a percepção de discentes iniciantes de um curso de Terapia Ocupacional em relação aos pacientes de saúde mental; revelou-se, nesse estudo, que o contato com a saúde mental nos períodos iniciais do curso contribuiu para maior compreensão em relação à pessoa com problemas mentais, além do desenvolvimento e do aperfeiçoamento de habilidades resolutivas.

Assim, considerando-se a amplitude e diversidade dos campos presentes na Terapia Ocupacional e as oportunidades que se colocam aos discentes durante a etapa de formação, que envolve o estágio profissional, compreende-se que aprofundar a reflexão acerca de novos formatos e de possibilidades de inserção e formação em serviço seja um dos desafios contemporâneos colocados para os envolvidos na formação dos profissionais.

Literatura recente indica que um dos elementos que contribuem na busca de fontes para discussão sobre a Terapia Ocupacional de um modo geral é a formação teórico-prática do profissional (PAN; LOPES, 2014), o que também inclui a integração entre o ensino nas instituiçóes e a prática vivenciada nos serviços durante a graduação.

Neste estudo, verificou-se ainda que, para a maioria dos discentes e egressos, a formação em saúde mental está articulada com as políticas públicas de saúde mental; porém, eles reconhecem o distanciamento entre o que aprendem durante a formação e o que confrontam nos estágios ou na experiência profissional recente, em que verificam que, em alguns contextos, a Reforma Psiquiátrica sequer se efetivou.

Assim, os resultados deste estudo, que reafirmaram a lacuna entre o que preconiza as políticas públicas de saúde mental e a realidade dos serviços, somam-se a estudos recentes, que apontam dificuldade ou ausência de mudanças no que se refere à efetivação das políticas públicas do campo, incluindo açóes de matriciamento, de saúde mental na atenção básica, bem como a construção de serviços substitutivos ao hospital desenvolvidos no contexto da comunidade, dentre outras açóes (CAVALHEIRO; GUIMARAES, 2011; MÂNGIA; MURAMOTO; MARQUES, 2010; PINTO; FERREIRA, 2010; MÂNGIA; MURAMOTO, 2009).

Na perspectiva de Constantinidis e Cunha (2013), esse distanciamento gera confronto entre a Terapia Ocupacional idealizada durante o processo de formação e as reais condiçóes dos serviços. Os resultados deste estudo acrescentam nesta dimensão, ao revelar também que tal distanciamento está relacionado à insegurança para atuação no campo.

Esse encontro entre o indivíduo que está em fase de aprendizado e o serviço, que, muitas vezes, contrapóe a política de saúde mental e é repleto de divergências, revela uma fragilidade da formação, quando não vem acompanhado de açóes propositivas e transformadoras por parte do discente ou do egresso. Tal oportunidade pode ser considerada como um processo comum que tem o potencial de trazer enriquecimento para a formação, uma vez que permite o avanço no desenvolvimento da reflexão, de ensaios e proposiçóes de estratégias de enfrentamento, dentre outras iniciativas. 
Importa aqui retomar a relevância das parcerias ensino-serviço para a formação dos profissionais da saúde em geral e, do terapeuta ocupacional, em particular. A ideia de parceria pressupóe a reunião de indivíduos com interesses em comum e, normalmente, a parceria entre IES e serviço acontece a partir da realização de estágios de discentes. Porém, a construção de um estágio profissional pode incluir dificuldades relacionadas tanto ao curso, no que se refere a matriz curricular, formação de docentes, disponibilidade de discentes e docentes, para a realização das atividades fora da IES, quanto ao serviço, como a ausência de técnicos para o acompanhamento e a realização de açôes no campo de práticas, e para o atendimento à população, o desconhecimento sobre a comunidade a ser assistida e sobre as diretrizes do Sistema Único de Saúde (SUS) (PIMENTEL; COSTA; SOUZA, 2011).

Para Albuquerque et al. (2008), a integração ensino-serviço é um trabalho realizado com discentes, docentes e profissionais dos serviços de forma conjunta e integrada, através de açôes acordadas entre os envolvidos, com foco na qualidade das açôes individuais e coletivas, na formação profissional e na satisfação dos profissionais das equipes dos serviços. Assim, a despeito dos desafios e contradiçóes da integração ensino-serviço, considera-se que esta é uma estratégia positiva para a formação, uma vez que o discente tem a possibilidade de vivenciar a realidade do campo no serviço, conforme orientam as DCN-TO, para tornar-se um profissional transformador desta realidade.

A literatura aponta que o atual contexto da assistência em saúde requer maior proximidade entre ensino e serviço devido à necessidade de uma formaçáo voltada para as demandas da população, em nível individual e coletivo, incluindo a familiarização com a organização do trabalho no serviço, no que se refere ao trabalho em equipe, ao acolhimento dos usuários, à resolubilidade, dentre outros (ALBUQUERQUE et al., 2008).

Nesta direção, os resultados deste estudo reforçam que a integração ensino-serviço é estratégia que precisa ser ampliada e mais presente na formaçáo do terapeuta ocupacional. Esta integração demanda por um profissional que contribua na busca de soluçóes que atendam as prioridades assistenciais tanto do território, quanto do SUS e das políticas públicas.

Por outro lado, é reconhecido que as dificuldades no processo de integração ensino-serviço são inevitáveis, devido à herança de um modelo de educação com foco na doença e não no sujeito. Pimentel, Costa e Souza (2011) sugerem a confrontação destas dificuldades através de novas possibilidades de ação, para lograr uma formação mais integrada, propositiva e coerente com a realidade dos usuários do SUS.

Os resultados deste estudo indicam que o modelo com foco na doença está presente nos serviços e não exatamente na formaçáo intramuros do terapeuta ocupacional. Tal aspecto também é reforçado pela literatura, que ressalta que o cenário de formação de profissionais da saúde nos serviços ainda está centrado em procedimentos que priorizam os fármacos e os equipamentos biomédicos às reais necessidades dos usuários. Não obstante, fica aqui evidenciado que ultrapassar esse limite é um desafio a ser assumido pelos cursos de graduação, que têm um papel de protagonismo nas transformaçóes necessárias.

Assim, apresenta-se como desafio a capacitação dos discentes, futuros profissionais, para lidar com a discrepância dos serviços em vistas à transformação e ao avanço dos mesmos. Compreende-se que esta dimensão está colocada tanto para a Terapia Ocupacional como também para outras especialidades envolvidas neste campo.

Importa problematizar, entâo, sobre como avançar neste processo de capacitação, efetivamente formando um aluno ativo, transformador, crítico, com domínio conceitual e prático, dentre outros; e também acrescentar a esta formação uma dimensão que implica posicionamentos na própria prática em um contexto contraditório, que é repleto de avanços, mas com muitas dificuldades e obstáculos a serem ultrapassados. Assim, há concordância com as consideraçóes de Constantinidis e Cunha (2013), que destacam, como desafio da formaçáo do terapeuta ocupacional, o preparo para equacionar as questôes relacionadas às condiçôes ideais e reais que compóem a rotina dos serviços, o que inclui o empenho na transformação da assistência em saúde, conforme as demandas apresentadas pela populaçáo.

No entanto, fica claro também que muito está demandado para além da formação dos profissionais deste campo e aponta-se que tanto as políticas do setor como os meios para viabilizá-las são açóes fundamentais, que fazem parte da esfera da gestão em diferentes níveis.

\section{Considerações finais}

Os resultados deste estudo acrescentam ao conhecimento da área e evidenciam a positiva opinião de discentes de cursos de graduação em Terapia Ocupacional sobre a formação em saúde mental.

Ainda que limitado a cursos localizados no Estado de São Paulo, este estudo contou com a participação de alunos concluintes e egressos, que revelaram um 
envolvimento crítico com sua formação, expresso nas diferentes questôes que lhes foram apresentadas. A disposição em apresentar comentários, tecer considerações e enviar sugestôes revela também o comprometimento destes jovens com a produção de conhecimento, táo necessária na área.

Considera-se que este estudo oferece subsídios para o desenvolvimento de novas investigaçôes e reflexốes sobre a formação do terapeuta ocupacional em saúde mental, considerando-se a demanda pelo empreendimento de novas estratégias, que atendam as peculiaridades de um campo amplo, diverso e em constante transformação.

\section{Referências}

ALBUQUERQUE, V. S. et al. A Integração ensino-serviço nenhum contexto dos processos de mudança na formação superior dos profissionais da saúde. Revista Brasileira de Educação Médica, Rio de Janeiro, v. 32, n. 3, p. 356-362, 2008.

ALMEIDA, M. M. et al. Da teoria à prática da interdisciplinaridade: a experiência do Pró-Saúde Unifor e seus nove cursos de graduação. Revista Brasileira de Educação Médica, Rio de Janeiro, v. 36, n. 1, p. 119-126, 2012.

BALLARIN, M. L. G. S.; CARVALHO, F. B. C. Consideraçōes acerca da Reabilitaçáo Psicossocial: aspectos históricos, perspectivas e experiências. In: CAVALCANTI, A.; GALVÂO, C. Terapia Ocupacional: fundamentaçấo e prática. Rio de Janeiro: Guanabara Koogan, 2007. p. $162-170$.

BARDIN, L. Análise de conteúdo. Lisboa: Ediçōes 70, 1977.

BELTRAN, R. O. et al. The effect of first year mental health fieldwork on attitudes of occupational therapy students towards people with mental illness. Australian Journal of Occupational Therapy, Australia, v. 54, n. 1, p. 42-48, 2007.

BERTAGNONI, L. et al. Núcleo de Apoio à Saúde da Família e Saúde Mental: itinerários terapêuticos de usuários acompanhados em duas Unidades Básicas de Saúde. Revista de Terapia Ocupacional da Universidade de São Paulo, São Paulo, v. 23, n. 2, p. 153-162, 2012.

BRASIL. Ministério da Educação - MEC. Conselho Nacional da Educaçáo. Resolução CNE/CES 6, de 19 $\mathrm{DE}$ fevereiro de 2002. Institui diretrizes curriculares nacionais do curso de graduação em Terapia Ocupacional. Diário Oficial [da] República Federativa do Brasil, Brasília, DF, 04 mar. 2002. Seção 1, p. 12. Disponível em: <http://portal.mec.gov.br/cne/arquivos/pdf/ CES062002.pdf >. Acesso em: 30 out. 2015.

BRASIL. Ministério da Educaçấo - MEC. Padrão minimo de qualidade para os cursos de Terapia Ocupacional. Brasília: MEC, 1997. Disponível em: <http://portal.mec.gov.br/ sesu/arquivos/pdf/pad_qua.pdfs. Acesso em: 30 out. 2015.
BUENO, A. R. Terapia ocupacional no campo da saúde mental infanto-juvenil: revelando as ações junto aos Centros de Atenção Psicossocial Infanto-juvenil (CAPSi). 2013. 145 f. Dissertação (Mestrado em Terapia Ocupacional) - Universidade Federal de São Carlos, São Carlos, 2013.

CAMPOS, R. O. Clínica: a palavra negada - sobre as práticas clínicas nos serviços substitutivos de saúde mental. Saúde em Debate, Rio de Janeiro, v. 25, n. 58, p. 98-111, 2001.

CARDOSO, B.; CARRETA, R. Y. D. Terapia Ocupacional no Programa de Saúde da Família - a construçāo de um campo de açáo social na perspectiva da atençáo primária. In: CONGRESSO BRASILEIRO DE TERAPIA OCUPACIONAL, 10., 2007, Goiânia. Anais.. Goiás: Kelps, 2007. CD-ROM.

CARVALHO, V. C.; MATSUKURA, T. S. Identificando práticas dos terapeutas ocupacionais inseridos no contexto da atenção básica em saúde. 2011. Trabalho de Conclusão de Curso (Graduaçáo em Terapia Ocupacional) - Universidade Federal de São Carlos, São Carlos, 2011.

CAVALHEIRO, M. T. P.; GUIMARÃES, A. L. Formação para o SUS e os desafios da integraçáo ensino-serviço. Caderno FNEPAS, Rio de Janeiro, v. 1, p. 19-27, 2011.

CECCIM, R. B.; FEUERWERKER, L. C. M. Mudança na graduaçáo das profissóes de saúde sob o eixo da integralidade. Cadernos de Saúde Pública, Rio de Janeiro, v. 20, n. 5, p. 1400-1410, 2004.

CONSTANTINIDIS, T. C.; CUNHA, A. C. A formação em terapia ocupacional entre o ideal e o real. Revista de Terapia Ocupacional da Universidade de São Paulo, São Paulo, v. 24, n. 2, p. 149-154, 2013.

DRUMMOND, A. F.; RODRIGUES, A. M. V. N. Os desafios da implantaçấo de uma proposta de flexibilização curricular nos cursos de terapia ocupacional. Revista de Terapia Ocupacional da Universidade de São Paulo, São Paulo, v. 15, n. 3, p. 106-111, 2004.

GOZZI, A. P. N. F. O processo de trabalho do terapeuta ocupacional na rede de saúde mental: focalizando a avaliação inicial. 2013. 119 f. Dissertação (Mestrado em Terapia Ocupacional) - Universidade Federal de São Carlos, São Carlos, 2013.

HAHN, M. S. O processo de escolha de áreas de especialidade dos recém-graduados em terapia ocupacional: a opção pela Psiquiatria e Saúde Mental. 1999. 196 f. Tese (Doutorado em Psiquiatria) - Universidade Estadual de Campinas, Campinas, 1999.

LOPES, R. E. Cidadania, Politicas Públicas e Terapia Ocupacional, no contexto das açōes de saúde mental e saúde da pessoa portadora de deficiência, no Município de São Paulo. 1999. 539 f. Tese (Doutorado em Educação) Universidade Estadual de Campinas, Campinas, 1999.

MÂNGIA, E. F; MURAMOTO, M. T. Modelo de matriz: ferramenta para a construção de boas práticas em saúde mental comunitária. Revista de Terapia Ocu- 
pacional da Universidade de São Paulo, São Paulo, v. 20, n. 2, p. 118-125, 2009. http://dx.doi.org/10.11606/ issn.2238-6149.v20i2p118-125

MÂNGIA, E. F; MURAMOTO, M. T.; MARQUES, A. L. M. Formação profissional e serviços de saúde mental no SUS: estudo sobre a inserção de egressos do Curso de Terapia Ocupacional da FMUSP. Revista de Terapia Ocupacional da Universidade de São Paulo, São Paulo, v. 21, n. 2, p. 148-157, 2010.

MARINS, S. C. F.; EMMEL, M. L. G. Formação do terapeuta ocupacional: acessibilidade e tecnologias. $C a$ dernos de Terapia Ocupacional da UFSCar, São Carlos, v. 19, n. 1, p. 37-52, 2011.

MATEUS, M. D. Levantamento das politicas e recursos em saúde mental no Brasil. 2009. 256 f. Tese (Doutorado em Psiquiatria) - Universidade Federal de São Paulo, São Paulo, 2009.

MATEUS, M. D.; MARI, J. J. O sistema de saúde mental brasileiro: avanços e desafios. In: MATEUS, M. D. Politicas de saúde mental: baseado no curso Políticas públicas de saúde mental, do CAPS Luiz R. Cerqueira. São Paulo: Instituto de Saúde, 2013. p. 20-55.

NAYAR, S. An examination of the preparedness for practice of new zeal and new graduate occupational therapists: a report for the Occupational Therapy Board of New Ze- aland. Auckland: Faculty of Health and Environmental Sciences, AUT University, 2011. Final Report.

OLIVER, F. C. et al. Formação do terapeuta ocupacional para o trabalho na Atençáo Primária à Saúde (APS): contribuiçóes para o debate. Cadernos de Terapia Ocupacional da UFSCar, São Carlos, v. 20, n. 3, p. 327-340, 2012. http://dx.doi.org/10.4322/cto.2012.033.

PAN, L. C.; LOPES, R. E. O ensino de Terapia Ocupacional Social nas Universidades públicas do Estado de São Paulo. Revista de Terapia Ocupacional da Universidade de São Paulo, São Paulo, v. 24, n. 2, p. 103-111, 2014. http:// dx.doi.org/10.11606/issn.2238-6149.v24i2p103-111.

PIMENTEL, A. M.; COSTA, M. T. B.; SOUZA, F. R. Terapia Ocupacional na Atenção Básica: a construção de uma prática. Revista de Terapia Ocupacional da Universidade de São Paulo, São Paulo, v. 22, n. 2, p. 110-116, 2011.

PINTO, A. T. M.; FERREIRA, A. A. L. Problematizando a reforma psiquiátrica brasileira: a genealogia da reabilitação psicossocial. Psicologia em Estudo, Maringá, v. 15, n. 1, p. 27-34, 2010. http://dx.doi.org/10.1590/ S1413-73722010000100004.

SAMPIERI, R. H.; COLLADO, C. F.; LUCIO, P. B. Metodologia de pesquisa. São Paulo: Mc Graw Hill, 2006.

\section{Contribuição dos Autores}

Thelma Simôes Matsukura: orientação, concepção do trabalho, organização e análise dos dados, redação e revisão do texto. Sarah Raquel Almeida Lins: concepção do trabalho, coleta, organização e análise dos dados, elaboração e redação do texto. As autoras aprovaram a versão final do texto.

\section{Notas}

${ }^{1}$ Este estudo está vinculado à Pesquisa de Mestrado: Formação acadêmica do terapeuta ocupacional no campo da saúde mental, realizado junto ao Programa de Pós-Graduação em Terapia Ocupacional da Universidade Federal de São Carlos, que contou com o apoio da Coordenação de Aperfeiçoamento de Pessoal de Nível Superior (CAPES)

${ }^{2} \mathrm{O}$ estudo foi submetido ao Comitê de Ética em Pesquisa em Seres Humanos e aprovado sob o Parecer n. ${ }^{\text {3 } 321.653 .}$

${ }^{3}$ Dissertação de Mestrado de Sarah Raquel Almeida Lins intitulada "Formação acadêmica do terapeuta ocupacional no campo da saúde mental”, desenvolvida junto ao Programa de Pós Graduação em Terapia Ocupacional da Universidade Federal de São Carlos (PPGTO-UFSCar).

${ }^{4}$ Levantamento realizado em 22/ago./2013, onde foram identificados 22 cursos de graduação em TO em atividade no Estado de São Paulo. 